\title{
Elderly person's forward-looking and self-fulfilling life while living with chronic Illness
}

Hiroko Sugimoto ${ }^{1 *}$, Yuko Yasuhara ${ }^{2}$, Tetsuya Tanioka², Rozzano Locsin ${ }^{2}$ and Soichi Honda ${ }^{3}$

*Correspondence: hirokos1014@outlook.jp

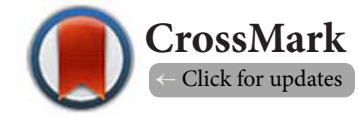

'Kamona elementary school, Tokushima, Japan.

${ }^{2}$ Institute of Biomedical Sciences, Tokushima University, Tokushima, Japan.

${ }^{3}$ Minami Hospital, Tokushima, Japan.

\begin{abstract}
Background: In contemporary Japan, the nuclear family continues to be the dominant family model which started during the high economic growth era (1955 1973). This situation diminished the opportunities for children to experience and know the life style of elderly persons. Sharing experiences and knowledge of older persons can provide helpful hints about how to live healthier lives. This study described the distinctive characteristics of an elderly person who is living a fulfilling life despite chronic illness.

Methods: In August 2017, nine elderly community-dwelling elderly who met the inclusion criteria of being chronically ill and leading positive and self-fulfilling lives were selected. They showed good sleep quality and health-related quality of life (HRQOL) scores, and managed to lead positive and self-fulfilling lives. This study was about one of the nine elderly persons whose narrative distinctly described the evolution of life events and experiences of personal living. Analysis followed the case description method.

Results: After a major health crisis, the selected participant realized an appreciation of his own mortality, providing the opportunity to re-examinine his life habits and discover new pleasures through interactions with friends. Despite the changes from a major health crisis, he maintained a positive outlook on life and strove to be forward-looking, inspired by the parting words of his older brother who died in World War II. It appeared that chronic illness at a later stage in life leads persons to reflect on their past, revisit their philosophy of life and the ways they lived their lives.

Conclusions: In order to lead self-fulfilling lives even while disease-stricken, older persons need a setting that allows them to re-tell their life stories often through reminiscence therapy. By listening to these stories, the children and their guardians can have the opportunity to appreciate and re-examine their own contemporary lifestyles and consider their future courses in life. This typical case exemplified having a chronic illness and living life positively.

Keywords: Chronically ill elderly persons, active lifestyle, qualitative research, case description study

In contemporary Japan, the nuclear family continues to gain dominance as the typical family model, thereby reducing opportunities for children to share the experiences and knowledge of the elderly [1]. The life experiences of older persons who made Japan's high economic growth period from 1955 to 1973 is a reality, providing helpful hints to children on how to lead healthier lives in recognizing the power of the lives of the elderly, their precious experiences in overcoming difficult times, where there was not enough food and poor hygienic

conditions was not uncommon.

A previous study [2] described the influence of chronic disease, sleep quality, health-related quality of life (HRQOL) and daily living activities of community-dwelling persons over 55 years of age on living fulfilling lives. The findings showed that good sleep quality was related to the participants' feeling-for-theirage, in that, because they felt younger physically, they were able to sleep better. Moreover, a favorable factor for physical HRQOL was the participants' feelings of being younger than their actual age.
\end{abstract}

\section{Introduction}


Sugimoto et al. Journal of Nursing 2018,

Other previous studies have shown that the aging process is often accompanied by diminished sleep quality and irregular sleep patterns [3-5], and that as age increases, physical HRQOL declines [6-8]. Furthermore, sleep problems were significantly correlated with chronic diseases, such as depression $[5,9]$, heart diseases $[5,9,10]$, arthritis $[5,9,10]$, and lung diseases $[9,10]$. It was also reported that the presence of chronic or serious diseases significantly lower HRQOL [11-13]. The results of these studies declare that participants who manifest good sleep quality and high HRQOL scores may lead lives of self-fulfillment in spite of chronic illnesses. These results suggest that a clarification of the distinctive characteristics of daily living activities and philosophy of life may lead the younger generation, including children and their guardians to consider their own daily living activities as influencing future healthy living.

This case study sought to illuminate the distinctive characteristics of lifestyles and daily life activities of communitydwelling elderly persons who led forward-looking and selffulfilling lives despite being chronically ill.

\section{Methods}

\section{Case description/presentation}

This case description presentation is part of a larger study, in which an initial sample of 161 patients in the outpatient department, age 55 years and older who were being treated at Hospital " $A$ " for various chronic ailments [2], were screened. Of these, 66 participants were selected, those who had PSQI-J (Japanese version Pittsburgh Sleep Quality Index) scores of less than six $[14,15]$. The PSQI global score range from 0-21, with higher scores indicating worse sleep quality, and scores of less than 6 indicating no significant sleep disturbance. Each participant's HRQOL was determined using the 8-item Short Form Medical Outcomes Study Health Survey for Japanese [16]. This provides two summary scores: a Physical Component Score (PCS) and a Mental Component Score (MCS). General population standardized scores for both the PCS and MCS range from 0 (worst) to 100 (best), with a mean of 50. From this group of participants, nine participants aged 69 80 years ( 5 males, 4 females) were selected based on the following inclusion criteria: Elderly participants diagnosed with a chronic disease and exhibiting scores of good sleep quality (from PSQI), and high Physical and Mental QOL (from their HRQOL scores).

The exclusion criteria included those participants with dementia, severe heart disease, and those under treatment for cancer. These identified chronic diseases were collected from the respective participants' electronic medical records and from the Observation List for early signs of Dementia [17] which was used by the primary physician to evaluate dementia among the participants.

\section{Procedure for data collection}

From the larger study, recruiting participants for this case presentation was done by obtaining information about the reasons for their positive outlook on life regardless of having chronic diseases. Nine participants qualified and a case was selected as representing an ideal story and situation using the inclusion and exclusion criteria.

The research study was conducted in August 2017. Data were collected through unstructured interviewsconducted in a private room provided by the research facility. Participants were asked to describe their past life experiences and purposes in life, and to reveal the "secret" behind their successes in leading positive and self-fulfilling lives despite living with chronic illness. These interviews were recorded on an IC recorder, transcribed, and analyzed.

From the nine interviews conducted, the researchers reached a consensus to select only those narratives that provided descriptions from participants who thought they were'younger than their age or thought that their feelings were those of the young person'. From these nine interviews, one narrative was selected as a typical description of the phenomenon of positive living despite chronic illness. This case presentation described what it was like for an elderly person to live with chronic disease and yet feel young for their age and have a positive outlook of life despite having chronic diseases.

\section{Analysis}

Data analysis was performed according to the narrative case method [18]. According to Reissman (2013), "narrative analysis allows for the systematic study of personal experience and meaning" (p. 185) [19]. An analysis of a singularly distinctive narrative of one of the participants was done to describe the life events and personal outlook, including the philosophy of life. From the verbatim transcription created from the participant interview, careful immersion in the interview data was done by listening and reading the transcripts of the interview. This interview focuses on Mr. A, who was ill but still living his life positively. The narrative data describes his approach to life from the time he was diagnosed to the present. His remarkable life history and equally remarkable view of life and important factors which led him to lead a self-fulfilling life even while disease-stricken were extracted from the narrative. It is important to note that the interview was done in the Japanese language from which analysis and interpretation was subsequently done. Translation of themes to English language was performed after the analysis including the verbatim descriptions that serve as audit trails.

\section{Ethical considerations}

The study was approved by the Ethics Committees of Tokushima University Hospital (No. 2648) and of Hospital "A", in Tokushima, Japan. The following information was carefully explained to all the participants, both orally and in writing: the purpose and content of the study; the voluntary nature of their participation; and, if they refused to participate, that they would not incur any disadvantages regarding patient care; the freedom to agree or disagree with the findings of the study, or its use in research 
presentations, and the rights of confidentiality of information. The participants provided written informed consents to participate. Furthermore, to avoid any burden on the participants, the interviews were restricted to a period of 30 minutes to 60 minutes, unless they needed to share more information.

\section{Results}

The narrative of one participant was selected as a singularly distinctive description of a positive example of the experience of having a chronic illness while living life in his own positive way. This participant experienced life by changing his living habits after he succumbed to cardiac problems. His experience with Myocardial Infarction led him to change and live a healthier life style for the past 15 years. One critically important life-change was his deepening appreciation of relating with his friends and enjoying his life with them. From this narrative, themes were identified and verified by at least two of the researchers, from which a consensus was reached as to the appropriate thematic statement accurately identifying the thematic meanings expressed by the participant.

\section{The Story of Mr. A}

Mr. A was a man in his 80 s with a medical history of angina pectoris, reflux esophagitis, irritable bowel syndrome, hyperlipidemia, allergic rhinitis, hyper-uricemia, and chronic gastritis. He was receiving outpatient hospital treatments for angina pectoris. He had a chronic illness, but had no sleep problems, and had good physical and mental quality of life (according to the PSQI and HRQOL tests results). In his younger days, Mr. A owned and managed a livestock-raising enterprise, eventually expanding his business from a small meat shop to a supermarket. Having retired and passed the business to his son, he is now engaged in farming together with his wife. During the interview, it was noted that he would sometimes smile while telling his story. Depending on the nature of his story, he would often appear to be enjoying himself, and at other times become overwhelmed by his emotions, as evinced by the tears in his eyes. This indicated a rich emotional life. His interview lasted 59 minutes.

\section{Findings of the study}

Thematic analysis and interpretation were conducted by the researchers in which confirmation by consensus was achieved pertaining to the appropriateness and accuracy of the themes identified.

\section{Theme 1: Narrow Escape from Death}

While alone in the mountains 15 years ago, Mr. A suffered a massive myocardial infarction. Feeling suffocated and having difficulty breathing, he mustered all his strengths, sought help, and was rescued. He described this experience as:

"Fifteen years ago, I suffered a heart attack...I was in the mountains when I suddenly felt sick. I had to do something; there was no one else around... It got so bad I couldn't breathe. The pain was excruciating, so much so that I seriously thought, "Am I going to die here"? I could not stand up at all. I grabbed the roots of the trees and the surrounding ferns, and crawled, dragging my body up the sloping mountain terrain. (redacted) Then, I grabbed a rock, smashed the car window, and kept pressing on the horn. Someone heard me. (redacted) An ambulance was called, and I was rushed to the hospital."

\section{Theme 2: An Occasion to Re-examine Life Habits and Health Attitudes}

For Mr. A the myocardial infarction and close shave with death turned into an impetus to pay more attention to his health. He reformed his dietary habits, included vegetables as essential part of his daily diet, and persisted in his new dietary regime.

"Everywhere I went, people advised me to always eat vegetables. Until that time, I had never purposefully eaten vegetables.

I was told to eat vegetables before every meal. Nowadays, I ask my wife to serve only the vegetables first before every meal. For example, for breakfast, we'll have 'miso' soup, some ort of boiled or stewed dish, and fish. After I've finished eating the vegetables, I ask her to bring out the other dishes. That way, l end up eating a lot of vegetables, since there's nothing else on the dining table. This has become a habit of mine. Even when we dine out, or travel, or wherever we go, I always order the vegetables first, and unless I finish eating my vegetables, I won't touch anything else. I decided to develop this habit on my own. (redacted) When I was younger, I hardly ever thought about my health. Since that time, it has become a permanent part of my consciousness. Managing my health...it's now something I seriously care about."

Furthermore, Mr. A quit smoking intentionally hoping to prolong his life. As an incentive to sustain the cessation of his smoking habit, he began saving his "cigarette money" and using it for traveling instead.

\begin{abstract}
"The doctor said I had to quit smoking. 'If you don't stop, you won't get well; you'll die.' That's what he told me. It was hard in the beginning, but I did as I was told. (redacted) 'Tobacco leaves turning into smoke disappearing into thin air, what a waste!' I thought. The family agreed with me, and every day now... I set $¥ 500$ aside, telling myself 'With this, I'll be going on a trip."'
\end{abstract}

\section{Theme 3: Improving Life Habits Can Lead to A Wider Circle of Friends}

The money saved by giving up smoking allowed Mr. A the opportunity to travel with old and new friends. He reported that never before has he experienced such an extensive range of social interactions as now.

"Whenever we travel abroad, a local tour guide is usually hired. Sometimes we'll click, and the guide will ask me to visit 
Sugimoto et al. Journal of Nursing 2018,

again and offer to show me around as a friend... (redacted) These days, considering my age, I am wary about traveling alone, so l'll ask an old classmate from grade school to go on a trip with me, around once a year... it's fun, but once in a while, someone else in my circle will ask to tag along if I'm planning to travel, regardless of where I'm going. So even if I don't invite anyone, someone will come along and ask to join me on a trip somewhere. It's just perfect. Having someone to talk to is great."

\section{Theme 4: Not Giving Up and Striving With A Forward- Looking Attitude}

For Mr. A, doing one's best and striving with a forward-looking attitude are very important. He has lived a life guided by these ideals. Even as he lived a life weighed down by illnesses, he asserted the importance of these ideals.

"Disregarding my parents' objections... at the age of 24, I borrowed 40 million yen and started a stock raising business. (redacted) Well, I was able to build a comfortable life that kept up with the Joneses....You know, it's not good for people to be alone... I think if people are not engaged in some kind of activity, they won't survive... I think the way human beings manage their feelings matters a lot. When it comes to our health, I think we need to be forward-looking. When we get sick, first of all, I think we have to adopt a fighting attitude: "No, I'm not going to let this illness defeat me!". (redacted)... At any rate, I think perseverance is essential. Don't give up so easily... (redacted) When my father was dying, he said, 'Don't worry at all. All the debts have been paid.' He departed this world with peace of mind. I thought that was uniquely admirable. (redacted) I believe that striving with a forward-looking attitude is crucial."

\section{Theme 5: Constant Strength in the Face of Adversity Was His Older Brother's Parting Words}

Having retrospectively examined his past, Mr. A recalled the parting words of his older brother who left home to fight in the war and never came back. These words come back to him whenever he faces adversity.

\footnotetext{
"'Brother, please don't go,' I pleaded. He replied, 'I won't be coming back alive. Take good care of Mom and Dad. You have to do your best!' Those were his last words to me. I believe his having said those last words to me, and my remembering them, enabled me to do my best. (redacted) They were only a few words, but they affected my future tremendously... Whenever things got tough, recalling these few words always made me do my best."
}

\section{Discussion}

Mr. A suffered a massive myocardial infarction that brought him to the brink of death. This experience was transformed into an opportunity to reassess his daily life habits, especially his dietary habits. With his wife's cooperation, he started eating vegetables, and contrived to increase his vegetable intake.
Moreover, his illness became an impetus for him to nurture health awareness, resulting in a desire to take the management of his health into his own hands. It has been reported that patients suffering from chronic cardiac insufficiency recognize the physical limitations and the new lifestyle imposed by their condition, and flexibly adapt to their altered circumstances [20]. Furthermore, it was also reported that, through the experience of illness, patients with asymptomatic cerebrovascular disease who underwent preventive surgery look back at how they managed their health, and recognize the need to redirect their health awareness toward the maintenance and reinforcement of good health. Toward that end, they are able to visualize behavioural changes [21]. Mr. A's experience of illness was so acute that he visualized the possibility of his own death. This experience culminated in changes to his views on health, to an extent that even surpassed results reported by previous prospective studies, and the permanence of improved life habits in his daily life.

Another improvement in his life habits was the cessation of smoking. Not only was he able to stop smoking, he was also able to set aside money previously budgeted for cigarettes, and save for trips that he enjoyed in the company of friends. While behavioural modification therapy is one of the treatments available for smokers [22], this study revealed that in Mr. A's case, the substitution of smoking with a new source of enjoyment sustained a continual abstention from smoking. Positive motivation is a crucial factor in health management [23], as demonstrated by Mr. A, who was able to discover ways to develop new and desirable health habits on his own.

Further, by traveling with friends, Mr. A gained more opportunities to converse with his peers and deepen friendships, enjoying interactions with people around him and the mutual understanding that resulted. It has been reported that for community-dwelling elderly persons, the abundance of friends contributes to a decrease in illnesses [24]. It has also been reported that people with an extensive network of social relationships tend to have higher levels of subjective happiness [25], and that elderly persons with a high level of subjective health feel less isolated [26]. Although they may have wives and children, by also having social interactions with friends, the elderly can maintain a more stable state of mental health.

Based on his business experience and the health crisis he survived, Mr. A stressed the importance of a forward-looking spirit. Profoundly inspired by the parting words of his older brother who died in World War II, he felt that remembering those last words helped him overcome the hard times in his life. His example demonstrates that positive thinking [27], a forward-looking outlook, and never giving up are important attitudinal expressions [28], and a determination to soldier on, and that a single experience or a few words can radically empower a person throughout life [29].

\section{Conclusion}

Mr. A, who was chronically ill but exhibited good sleep qual- 
Sugimoto et al. Journal of Nursing 2018,

ity and high HRQOL scores, had suffered a life-threatening illness. Subsequently, he reassessed his life habits, and found new ways of enjoying himself through social interactions with friends. Behind his success were his positive attitude and determination to move forward, impelling him to take a hands-on approach to the management of his own health, conscious that illnesses often go hand in hand with the process of aging. His narratives in this study portrayed his past, and crystallized his attitudes toward life and how he had lived his life. Such narratives of the elderly may be of benefit to the younger generation of children and their guardians, who, upon listening to them, may decide to reassess their current lifestyles and consider healthier alternatives for a better future.

As a future research focus, studies can also include the experiences of elderly persons with poor health-related quality of life and poor sleeping quality, and clarify what is the experience of living with chronic disease and possessing a positive outlook in life. Therefore, this provides a clearer description of living with a positive outlook in life, despite having chronic illness.

In furthering the value of learning from Mr. A's situation, it is important that visiting and home care/community nursing assessments should include questions about a person's outlook on life. Furthermore, nurses need to determine actions that could be performed, and identify concerns about the availability of resources if and when the individual person does not display a positive outlook on life. It is important that health teachings be considered that is focused on adaptive activities and other co-existing therapeutic regimens such as reminiscence therapy.

\section{Competing interests}

The authors declare that they have no competing interests.

Authors' contributions

\begin{tabular}{|l|c|c|c|c|c|}
\hline Authors' contributions & HS & YY & TT & RL & SH \\
\hline Research concept and design & $\checkmark$ & $\checkmark$ & -- & -- & -- \\
\hline Collection and/or assembly of data & $\checkmark$ & -- & $\checkmark$ & -- & $\checkmark$ \\
\hline Data analysis and interpretation & $\checkmark$ & $\checkmark$ & -- & $\checkmark$ & -- \\
\hline Writing the article & $\checkmark$ & $\checkmark$ & $\checkmark$ & -- & -- \\
\hline Critical revision of the article & $\checkmark$ & -- & $\checkmark$ & $\checkmark$ & -- \\
\hline Final approval of article & $\checkmark$ & -- & $\checkmark$ & -- & $\checkmark$ \\
\hline
\end{tabular}

Acknowledgements and funding

The authors would like to express their deepest gratitude to the participants of this study, and to all the staff at the Minami Hospital. Further gratitude is offered to the members of the nursing laboratory. This study was supported by the Japan Society for the Promotion of Science Grant-in-Aid Program (No. 17H00708).

Publication history

Editor: Pamela gail Hawranik, Athabasca University, Canada. Received: 10-Apr-2018 Final Revised: 07-Jun-2018

Accepted: 09-Jun-2018 Published: 30-Jun-2018

\section{References}

1. Ministry of Health, Labor and Welfare, Japan:2017 Comprehensive Survey of Living Conditions (In Japanese). I Pdf

2. Sugimoto H, Tanioka T, Yasuhara Y, Kurokawa A, Sato M, OzawaK, Locsin $\mathrm{R}$ and Honda $\mathrm{S}$. The relationship among chronic disease, feeling-fortheir-age, sleep quality, health-related quality of life and activities of daily living of community-dwelling persons over $\mathbf{5 5}$ years of age. Open Journal of Psychiatry. 2018; 8:20-34. | Article

3. Buysse DJ, Reynolds CF, 3rd, Monk TH, Hoch CC, Yeager AL and Kupfer DJ. Quantification of subjective sleep quality in healthy elderly men and women using the Pittsburgh Sleep Quality Index (PSQI). Sleep. 1991; 14:331-8. | PubMed

4. Neubauer DN. Sleep Problems in the Elderly. American Family Physician. 1999; 59:2551-2560. | Article

5. Newman AB, Enright PL, Manolio TA, Haponik EF and Wahl PW. Sleep disturbance, psychosocial correlates, and cardiovascular disease in 5201 older adults: the Cardiovascular Health Study. J Am Geriatr Soc. 1997; 45:1-7. | Article | PubMed

6. Kim D. Correlation between physical function, cognitive function, and health-related quality of life in elderly persons. J Phys Ther Sci. 2016; 28:1844-8. | Article | PubMed Abstract | PubMed FullText

7. Singer MA, Hopman WM and MacKenzie TA. Physical functioning and mental health in patients with chronic medical conditions. Qual Life Res. 1999; 8:687-91. | PubMed

8. Hopman WM, Harrison MB, Coo H, Friedberg E, Buchanan M and VanDenKerkhof EG. Associations between chronic disease, age and physical and mental health status. Chronic Dis Can. 2009; 29:108-16. | Pdf | PubMed

9. Foley D, Ancoli-Israel S, Britz P and Walsh J. Sleep disturbances and chronic disease in older adults: results of the $\mathbf{2 0 0 3}$ National Sleep Foundation Sleep in America Survey. J Psychosom Res. 2004; 56:497502. | Article | PubMed

10. Chiou JH, Chen HC, Chen KH and Chou P. Correlates of self-report chronic insomnia disorders with 1-6 month and 6-month durations in homedwelling urban older adults - the Shih-Pai Sleep Study in Taiwan: a cross-sectional community study. BMC Geriatr. 2016; 16:119. | Article | PubMed Abstract | PubMed FullText

11. Ellis C, Grubaugh AL and Egede LE. Factors associated with SF-12 physical and mental health quality of life scores in adults with stroke. J Stroke Cerebrovasc Dis. 2013; 22:309-17. | Article | PubMed

12. Wikman A, Wardle J and Steptoe A. Quality of life and affective wellbeing in middle-aged and older people with chronic medical illnesses: a cross-sectional population based study. PLoS One. 2011; 6:e18952. | Article I PubMed Abstract I PubMed FullText

13. Kim KJ, Heo M, Chun IA, Jun HJ, Lee JS, Jegal $H$ and Yang YS. The relationship between stroke and quality of life in Korean adults: based on the $\mathbf{2 0 1 0}$ Korean community health survey. J Phys Ther Sci. 2015; 27:309-12. | Article | PubMed Abstract | PubMed FullText

14. Doi Y, Minowa M, Uchiyama M and Okawa M. Development of the Pittsburgh Sleep Quality Index Japanese Version. Japanese Journal of Psychiatric Treatment. 1998; 13:755-763.

15. Doi Y, Minowa M, Uchiyama M, Okawa M, Kim K, Shibui K and Kamei Y. Psychometric assessment of subjective sleep quality using the Japanese version of the Pittsburgh Sleep Quality Index (PSQI-J) in psychiatric disordered and control subjects. Psychiatry Res. 2000; 97:165-72. | Article | PubMed

16. Fukuhara $S$ and Suzukamo Y. Manual of the SF-8 Japanese Version. Institute for Health Outcome and Process Evaluation Research, Kyoto. 2004.

17. Hopman-Rock M, Tak EC and Staats PG. Development and validation of the Observation List for early signs of Dementia (OLD). Int J Geriatr Psychiatry. 2001; 16:406-14. | PubMed

18. RiessmanCK. Narrative Analysis. Narrative, Memory \& Everyday Life. University of Huddersfield. 2005; 1-7.

19. Reissman CK. Analysis of personal narratives. Qualitative Research in 
Sugimoto et al. Journal of Nursing 2018,

Social Work. (2nd ed.). 2013; 168-191.

20. Jeon YH, Kraus SG, Jowsey T and Glasgow NJ. The experience of living with chronic heart failure: a narrative review of qualitative studies. BMC Health Serv Res. 2010; 10:77. | Article | PubMed Abstract | PubMed FullText

21. Yamamoto N. Meaning of illness: Experience of patients with asymptomatic cerebrovascular disease who underwent the preventive surgery. J. Jpn. Soc. Nurs. Health Care. 2004; 6:7-15.

22. Leventhal $\mathrm{H}$ and Cleary PD. The smoking problem: a review of the research and theory in behavioral risk modification. Psychol Bull. 1980; 88:370-405. | PubMed

23. Kahkonen $\mathrm{O}$, Kankkunen $\mathrm{P}$, Saaranen $\mathrm{T}$, Miettinen $\mathrm{H}$, Kyngas $\mathrm{H}$ and Lamidi ML. Motivation is a crucial factor for adherence to a healthy lifestyle among people with coronary heart disease after percutaneous coronary intervention. J Adv Nurs. 2015; 71:2364-73. | Article | PubMed

24. Demura $S$ and Sato $S$. Relationships between depression, lifestyle and quality of life in the community dwelling elderly: a comparison between gender and age groups. J Physiol Anthropol Appl Human Sci. 2003; 22:159-66. | Article | PubMed

25. Powdthavee N. Putting a price tag on friends, relatives, and neighbours: Using surveys of life satisfaction to value social relationships. The Journal of Socio-Economics. 2008; 37:1459-1480. | Article

26. Ikeda S, Ueki S and Shiba Y. An examination of urinary incontinence and psychosocial factors affecting self-rated health among older adults in need of support and long-term care at home. Japanese occupational therapy research. 2015; 34:509-518.

27. Hurt CS, Burn DJ, Hindle J, Samuel M, Wilson K and Brown RG. Thinking positively about chronic illness: An exploration of optimism, illness perceptions and well-being in patients with Parkinson's disease. Br J Health Psychol. 2014; 19:363-79. | Article | PubMed

28. Young $Y$ and Resnick B. Don't Worry and Be Positive: What helps the most in functional recovery one year after hip fracture? An exit interview. Rehabil Nurs. 2009; 34:110-117. | Article

29. Raina RS and Thawani V. The Zest for Patient Empowerment. J Clin Diagn Res. 2016; 10:FE01-3. | Article | PubMed Abstract | PubMed FullText

\section{Citation:}

Sugimoto H, Yasuhara Y, Tanioka T, Locsin R and Honda S. Elderly person's forward-looking and selffulfilling life while living with chronic Illness.

Journal of Nursing. 2018; 5:4.

http://www.hoajonline.com/nursing/2056-9157/5/4 